\title{
Games People Play: A Comparative Study of Promotional Game Participants and Gamblers
}

Dr. Beverly A. Browne, Marketing, Oregon State University Dr. Dennis Kaldenberg, Marketing, Oregon State University Dr. Daniel J. Brown, Marketing, Oregon State University

\begin{abstract}
This study examines the use of promotional games and contests as a form of hedonic consumption related to other gaming behavior. Discriminant analysis using a combination of demographics and gambling behavior identified age, lottery playing, and education as important predictors of promotional game playing. Compared to non-players, users of promotional games were younger, better educated, more likely to be part of families with children, and more likely to participate in legal gambling activities.
\end{abstract}

\section{Introduction}

Even though sales promotions are sometimes difficult to manage (Schultz and Robinson, 1982), promotion expenditures have grown dramatically in the last decade (Flanagan, 1988; Hartley and Cross, 1988; Stang, 1976; Stern, 1987). In particular, game-like consumer experiences, such as sweepstakes and contests, have become increasingly popular devices for increasing short-term sales (Enscoe, 1990). In 1989, it was estimated that sponsors spent 500 million dollars on promotional game management and prizes (Incentive, 1990). Other experts (reported in Ward and Hill, 1991) suggest that this estimate is conservative and that the total yearly amount spent on development, management, and promotion of sweepstakes alone is more than one billion dollars.

The variety of promotional games is great, ranging from instant-win but low-payoff scratch games to contests requiring considerable consumer effort (e.g., those involving the writing of advertising jingles). Although this array makes general description difficult, all games and contests attempt to generate consumer attention and excitement. The use of games in promotion involves unique problems, such as determining the appropriate magnitude of prizes, setting pay-off schedules, and assuaging consumer skepticism about the game's legitimacy. Developing workable strategies to deal with these issues clearly requires an adequate knowledge of the target for the promotion. Nevertheless, academic research on consumers of promotional games has been relatively neglected. This study uses survey data to examine the demographic characteristics of promotional game players. It suggests similarities between promotional game players and gamblers in demographics and needs for stimulation and concludes with recommendations for practitioners.

\section{Background}

In its pure sense game-playing is hedonic consumption, characterized by being spontaneous and pleasurable, providing feelings of competence and control, and by being distinct from work (Berlyne, 1968; Deci, 1975; Csikszentmihalyi, 1975). An increasing body of consumer research indicates that individuals vary in needs for stimulation and that these variations may be rooted in early experience and personality (Holbrook and Hirschman, 1982; Sheth, 1979). For example, Hirschman (1984) found past experience to be related to individual differences in needs for cognitive stimulation, sensory stimulation, novelty, and the composite of these needs (experience seeking). Some consumer researchers (Faison, 1977; Raju and Venkatesen, 1980) believe novelty seeking and experience seeking can be applied to understanding of consumer behavior, particularly in response to stimulus characteristics. Support for this view was provided by Raju (1980), who found relationships between needs for novelty and response to products and marketing communications, reduced repetitive behavior, and increased brand switching.

Ward and Hill (1991) have developed a model of consumer promotional game participation in which the intrinsic value of participation (having fun, being interested, and receiving feedback about competence) combines with extrinsic factors (e.g., the odds of winning) to mediate decisions to participate. The degree to which an individual sees the game as valuable is influenced by demographics, personality, and beliefs about games. Although the model provides an excellent basis for organizing theory and testing hypotheses, its assumptions are largely unexplored. The few published empiri- 
cal studies of marketing game/contest users concentrate on sweepstakes play and have investigated game playing from an atheoretical stance. To provide a sample of existing findings, Narayana and Raju (1985) found that sweepstakes players were employed in positions of higher status than persons who preferred another form of promotion (gifts). Howard and Barry (1990) found that consumer assessments of the probability of winning affected the consumer's evaluation the prize. In contrast to those who thought the probability of winning was high, contestants that had low expectations of winning inflated the value of the prize. As with gambling, negative relationships between promotional sweepstakes play, the financial well-being of the consumer, and economic prosperity have been reported (see Narayana and Raju, 1985).

While the academic literature concerning promotional game players is meager, the literature on gamblers is extensive, with a substantial portion focusing on sensation seeking and stimulation needs. As reviewed by Zuckerman (1979), high sensation seekers are more likely to gamble and tend to bet more in both actual and hypothetical gambling situations than low sensation seekers. Kallick-Kaufmann (1979) found that, among other characteristics, gamblers differed from nongamblers in thrill-seeking and perceptions of being more skilled. Other studies have implicated compulsiveness with gambling and game-playing in general (Faber, O'Guinn, Thomas, and Krych, 1987; Burns, Gillett, Rubenstein, and Gentry, 1990). In the Burns et al. study, compulsive lottery players (defined as purchasers of more than 15 lottery tickets per week) exhibited other compulsive behaviors including fantasizing about sudden wealth, compulsive buying, and participation in other forms of gambling.

Specific demographic profiles have also been associated with the various types of gambling. McConkey and Warren (1987) found that, for lotteries, nonplaying females were concentrated in retired households and had lower incomes. Heavy players tended to be middleaged and have higher incomes, while light players tended to have demographics that fell between the heavy and light players. Edmondson (1986) reported lottery players to be stimulated by increases in payoffs and media promotion of games. Gamblers who preferred high-stakes games like blackjack were more likely to be male and to believe they could increase their odds of winning through skill. Lower educational levels have been linked to gambling in a number of studies and reviews (Burns et al., 1990; Wells, 1989).

In the present study the characteristics of adults who play promotional games were examined with special attention to the relationship of participation to engaging in gambling activities. Demographic profiles of gamblers and promotional game participants were developed. Because lotteries resemble promotional games in form, accessibility, and skill requirements more closely than some other gambling games, we expected to find similarities between promotional game players and lottery ticket purchasers in demographic profiles. In addition, based on research linking personality and demographic factors with preferences for game-playing, it was hypothesized that promotional game playing would be associated with participation in games of chance with heaviest lottery players being the most likely to play promotional games. Knowledge of respondent gambling behavior was expected to improve predictions of promotional game playing.

\section{Method}

\section{Sample}

The data for the study came from a stratified statewide telephone survey of 3200 Oregon respondents conducted in 1990 . The sample was approximately equally divided between males and females and contained a wide distribution of ages (18 through 95 years, Mdn $=46$ years), education (less than high school, $13 \%$, through college and graduate school, 22\%) and occupations (laborer to professional). Median yearly income for the sample was $\$ 25,585$. Forty-three percent of the sample resided in a major metropolitan area (over 500,000 in population). Only five percent of respondents were members of a racial minority group. Comparisons to population statistics indicated that the sample was representative of the total population.

\section{Procedures and Analyses}

To obtain the sample, numbers were randomly selected from telephone directories (to ensure that selected numbers were in utilized sequences) and the number, one, was added to the telephone number to produce the actual telephone number called. Calls were made on different days and at different hours to ensure that the sample was representative of the entire state. In multiple person households, the respondent was that person, 18 or over, who had the most recent birthday. Sampling was conducted regionally, with 400 people sampled in each of eight regions of the state. Because some sampling areas were substantially smaller in total population, the data were statistically weighted to allow the results to be representative of the actual regional population.

Respondents were asked to provide information about their demographic characteristics (age, gender, marital status, education, income, children, and employment), and their gambling and promotional game playing behavior. Game playing was measured with a "yes-no" format using the following the question: "Please tell me whether or not you have played any of the following gaming activities during the past year." After which the following five games, were listed: "bingo", "horse or dog racing", "casino gambling", "any lottery games," and "consumer product games." Horse or dog racing and casino gambling involve skill (from the gambler's perspective). Lottery games and bingo represent pure chance gambling and were assumed to be the most similar to sweepstakes. The respondent who answered "yes" to the lottery game question was asked to report the number of times in the past month he/she played the games available within the state surveyed (Oregon). 
The lottery games included in the survey, Megabucks, Lotto America, and Instant Scratch Tickets, differed in the size of the payoff and the player's chance of winning. Megabucks, a high-stakes, state-sponsored lotto game in which a player bets $\$ 1.00$, offers a chance at a prize of at least a million dollars. Lotto America, a multistatesponsored lotto game, similar in form to Megabucks but with fewer chances to win, has a minimum prize of at least 2 million dollars. Instant Scratch Tickets, a state game with low pay-offs and better odds of winning, offers prizes which range from one dollar to several thousand dollars. Unlike the lotto games, players of Instant Scratch games can determine immediately if they have won a prize by removing the coating on the game piece. Respondents also recalled the frequency of play of each of these three games using a free response format. For purposes of analyses, lottery players were categorized as non-purchasers, lighter purchasers (once a week or less), and heavy purchasers (more than once a week). Promotional game players and those participating in other forms of gaming were divided into users and non-users.

Data collected for this study were analyzed using simple cross-tabulations, correlations, and discriminant analysis. Cross-tabulations and correlations were used to develop demographic profiles of gamblers and game players and examine the inter-relationship among variables. Discriminant analysis was employed to determine if the a priori defined groups (gamblers and promotional game players) differed with respect to a collection of discriminating variables. Linear combinations of independent variables best distinguishing between cases in the category of the dependent variable were found and the relative importance of each predictor variable in discrimination was calculated. Because the actual group memberships were known, percentages of correct classification, based on the equation, could be computed. A stepwise algorithm was used which selects the variable with the smallest Wilk's lambda from among those which satisfy the minimum $F$ value (1.0) necessary to enter the equation (Klecka, 1980).

\section{Results}

The weighted proportion of the survey population who reported playing promotional games was $16.5 \%$. Approximately $55 \%$ of the sample reported playing the combined state lotteries. Proportions of the sample reporting other forms of gambling were smaller, ranging from $6.9 \%$ (horse and dog betting) to $15.1 \%$ (casino gambling). All of the reported correlational relationships reported in this paper were significant at the .001 level; difference tests were significant at the .0001 level, unless otherwise stated.

A demographic portrait of respondents who engaged in gambling and promotional game playing was developed. These data partially supported the hypothesized similarity between promotional game players and lottery ticket purchasers. Promotional game playing was found to be inversely related to age; likewise, age was either unrelated or negatively related to lottery ticket purchase, depending on the specific lottery game. The average age for players of promotional games (mean $=38.9$ years) was significantly younger $(t=16.13, p<.001)$ than that of non-players (mean $=50.1$ years), with game-playing dropping off linearly with age. Promotional game players, however, were also significantly younger than the players any of the gambling games assessed in this study whose mean ages ranged from 43.3 years (racetrack bettors) to 52.3 (bingo participants). Males and females tended to play consumer promotional games and to purchase lottery tickets in equal numbers. Relationships between relevant variables are presented in Table 1.

Other age-related demographics were associated with game playing. Players of promotional games tended to be better educated than the players of the other games of chance included in this study, with the exception of bingo. Education was positively related to promotional game playing and negatively related to gambling. Respondents in households with children under the age of 16 were twice as likely to play promotional games as respondents in households without children, $23.9 \%$ and $12 \%$, respectively. Megabucks lottery ticket purchasers were also significantly more likely to have children under the age of 16 in the household; this was less true of other gambling groups.

Investigation of the relationship of occupation to consumer game playing indicated that respondents employed in agricultural occupations were the least likely to play promotional games $(7.5 \%)$; those employed in sales were the most likely to play $(26.3 \%)$. Professional/managerial and service workers were also more likely to be players of promotional games than other occupational categories (operatives, clerical, craftsmen, and laborers). Overall, employed persons (part or full-time) were much more likely to play promotional games and gamble than were unemployed persons. No clear pattern existed between playing consumer product games and total household income. Rather, income had a small positive relationship to participation in casino gambling, was unrelated to lottery play, and was negatively related to playing bingo.

The hypothesis that playing promotional games would be associated with gambling behavior and with preferences for specific types of gambling was supported. In all cases, those who engaged in gambling behavior were also more likely to play promotional games than nongamblers. On the average lottery players were nearly three times more likely to report participating in promotional game playing; racetrack betters and casino gamblers had double the participation rates of nongamblers. Heavy users of lotteries were the most likely of any group to play promotional games. As might be expected, there were positive relationships between the various forms of gambling, especially between various lotteries. Data indicating percent of non-users, light users ( 1 to 4 times per month), and heavy users (5 or more times per month) of lotteries reporting participation in consumer product games is presented in Table 2.

Discriminant analysis of players and nonplayers of promotional games indicated that the factors most 
TABLE 1

Correlation Matrix for Promotional Game Playing and Related Variables

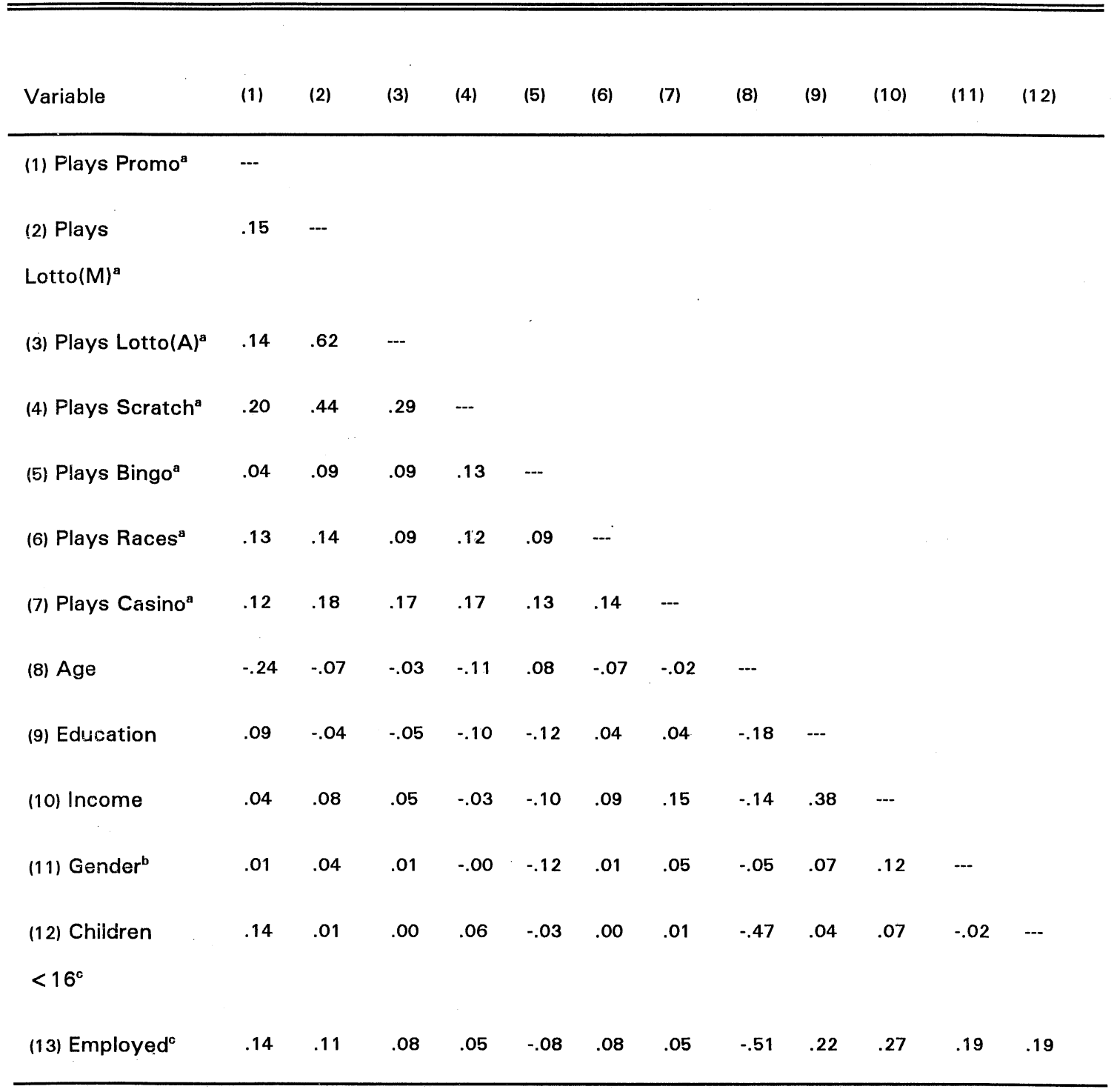

- Doesn't play=0, Play=1. $(M)=$ Megabucks, $(A)=$ Lotto America.

b Male $=1$, Female $=2$.

c $\mathrm{No}=0, \mathrm{Yes}=1$.

Correlations greater than .05 are significant at the $p<.001$.

predictive of playing promotional games were age and playing Instant Scratch state lottery games. Other variables which were significant discriminators of promotional game playing included: playing multi-state lottery, education, having children under age 16 , and engaging in racetrack betting. The discriminant function using these variables could correctly identify $65 \%$ of the promotional game players and $72 \%$ of the nonplayers.
Results of the discriminant analysis are displayed in Table 3. Knowledge of gambling behavior was an important criteria for identifying promotional game players. A regression which entered all of the demographic variables identified in this study explained $5 \%$ of the variance of promotional game playing; when the gambling variables were entered the explained variance increased to $10 \%$, a significant improvement ( $\mathrm{F}$ of 
Change $=27.4, \mathrm{p}<.001)$.

and still fit within legal limitations. Consumers could

TABLE 2

Percent of Lottery Users and Nonusers Playing Promotional Games

\begin{tabular}{lcccccc}
\hline \hline Type of game & Non-users & Light users $^{\mathrm{a}}$ & ${\text { Heavy } \text { users }^{\mathrm{b}}}$ & $x^{2}$ & $\mathrm{df}$ & $\mathrm{p}$ \\
\hline Scratch Tickets & $8.7 \%$ & $21.2 \%$ & $31.0 \%$ & & & \\
& $(\mathrm{~N}=1453)$ & $(\mathrm{N}=1429)$ & $(\mathrm{N}=316)$ & 135. & 2 & .001 \\
& & & & 6 & \\
& $11.8 \%$ & $21.1 \%$ & $28.4 \%$ & & & \\
Megabucks & $(\mathrm{N}=1845)$ & $(\mathrm{N}=1037)$ & $(\mathrm{N}=316)$ & 77.8 & 2 & .001 \\
& & & & & \\
Lotto America & $13.6 \%$ & $25.0 \%$ & $26.8 \%$ & & & \\
& $(\mathrm{~N}=2407)$ & $(\mathrm{N}=640)$ & $(\mathrm{N}=150)$ & 60.5 & 2 & .001 \\
\hline
\end{tabular}

light users played once a week or less

bheavy users played more than once a week.

\section{Managerial Implications}

According to Jagoda and Daykin (1985) the two most important questions for those who are planning prize promotions is whether the strategy will be appropriate for the target audience and whether it will increase sales. Our results suggest that the targeting of promotional efforts could be improved by a combination of life-style (in this case, gaming) and demographic variables. A summary of the important findings of the study relating to this issue appears in Table 4. Paradoxically, the existence of a game-playing consumer raises the specter of professional game entrants. Professional entrants are the most likely to be game-players generally and least likely to participate as an added benefit of product purchase, thus decreasing the effectiveness of the game. Managers for whom this is an important consideration may wish to use contests requiring skill, where proof of purchase can be demanded, instead of other game formats.

The existence of a game-playing consumer may have other implications for structuring promotions and for product introductions. One possibility suggested by the study is that increase, rather than reduction, of perceived risk may be an appropriate tactic for some market situations. Based on investigations of the effects of odds on consumer perceptions (Howard and Barry, 1990), a limited increase in the perception of risk in playing a promotional game may increase both the hedonic value of the promotion and the perceived value of the product/prize associated with the promotion for some consumers. Risk manipulation can be done by manipulating odds or steps to complete the entry form also be offered a choice of games with different levels of risk, thus accommodating both high and low risk seekers. In addition, offering multiple chances for winning could generate interest among game players. Multiple-entry sweepstakes (e.g., the Benson and Hedges 100s sweepstakes), offering different prizes for each of the entries in the combination, are an effective way to increase involvement, perceptions of chances of winning, and the excitement of the game. The value of the attention given the game might be particularly great for products that are waning in consumer interest or that are vying for shelf space.

TABLE 3

Discriminant Analysis of Variables Related to Promotional Game Playing

\begin{tabular}{lccc|}
\hline \hline Variable & $\begin{array}{c}\text { Standardized } \\
\text { Canonical } \\
\text { Liscriminant } \\
\text { Coefficient }\end{array}$ & $\begin{array}{c}\text { Correlation } \\
\text { Between } \\
\text { Function and } \\
\text { Variable }\end{array}$ \\
\hline Age & .92 & -.47 & -.63 \\
Plays Scratch & .92 & .44 & .59 \\
Plays Lotto(A) & .91 & .30 & .45 \\
Education & .91 & .26 & .27 \\
Plays Races & .91 & .26 & .38 \\
Plays Casino & .90 & .19 & .36 \\
Children Under 16 & .90 & .17 & .41 \\
Plays Bingo & .90 & .09 & .13 \\
\hline
\end{tabular}


TABLE 4

Summary of the Major Findings

\title{
Gaming Behavior and Promotional Game Participation:
}

Gamblers were more likely to play promotional games. Heavy lottery usage was related to promotional game participation. Promotional game players were younger and better educated than gamblers.

\section{Demographic Factors Related to Promotional Game Participation:}

\author{
Households with children $<16$ years of age \\ Age 18-35 (60\% of game participants) \\ Employed full- or part-time \\ Occupation in sales ( $26.3 \%$ of game participants) \\ High school or college education \\ No gender or income correlates
}

Because losing decreases the hedonic effect of a game, particular attention should be provided to treatment of the losers in promotional games. Negative feelings, developed as a result of losing, might be avoided by careful game design and promotion that does not imply excessive control over the outcome of the game. Games that offer a second chance at winning through continuity programs soften the blow of losing. Furthermore, offering losers small prizes or some other form of positive feedback is likely to increase the hedonic value of play and, therefore, is desirable. Small prizes or additional chances at winning that can only be obtained on the next visit to the supermarket or other retail outlet have the additional advantage of encouraging repeat purchase.

\section{Conclusions}

One assumption underlying this study was that all games contain elements of play that may be differentially attractive to consumers. Our results suggest the existence of a consumer segment that tends to be attracted to promotions involving playful experiences (sweepstakes-like games and contests). Game-players were younger and more educated than non-game players and were more likely to participate in games of chance, especially various forms of the lottery. Although the findings are not conclusive, they suggest that some contest and sweepstakes participants resemble gamblers psychographically (Burns et al., 1990; Zuckerman, 1979). In addition, the results were similar to those of McConkey and Warren (1987), who found inconsistent relationships between gaming and income and positive relationships between full time employment and gam- bling. Players of promotional games tended to be employed and better educated than non-players. The relationship between education and playing promotional games may reflect the demographics of the game players in so much as younger adults tend to be better educated.

The relatively small proportion of persons reporting participation in promotional games replicates other work (Gould, 1988). However, even this percentage may represent an important increase in attention to the company or product on the part of consumers. The significantly greater interest in consumer games by younger persons and persons with children has implications for the use of games. If a major share of a firm's target market consists of children or families with children, promotional contests and games would be an effective method of increasing sales.

Several limitations to the findings of the study should be noted. First, the study is based on self-report data and is subject to the report biases typical of this methodology, particularly the vagaries of human memory and the influence of social desirability sets. The likely effect of these report biases would be to reduce the reported incidence of game playing. Second, the actual relationships in the study, although highly significant, were relatively small. Thus, the functional value of the factors investigated must be evaluated with caution. Third, since gambling by definition requires economic stake not typical of a promotional game, there are limits both to the degree that promotional game playing resembles true gambling and to resemblances between gamblers and promotional game players. 


\section{Suggestions for Future Research}

In the light of this study, a more direct test of the effects of consumer experiential orientation on preference for participation in game-like promotions would be desirable. One potentially fruitful direction might be to examine the consumer's experience-seeking tendencies, perception of risk, and the expected value of participation in promotional games in an experimental setting where it is possible to control and manipulate risk conditions. Such studies have been conducted to examine other kinds of gaming behavior. In addition, this study asked about consumer product games in general. Because available games are quite various in their specific characteristics, extensions of the research might examine the relationships between these characteristics and consumer characteristics, attitudes, and participation rates. In particular, the appeal of specific types of games to different kinds of consumers would be a useful area of investigation.

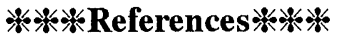

1. Berlyne, Daniel E., "Laughter, Humor, and Play," in Handbook of Social Psychology, Vol. III. Gardner Lindzey and Elliot Aronson (Eds.), Reading, MA: Addison Wesley, pp. 795-852, 1968.

2. Burns, Alvin C., Gillett, Peter L., Rubenstein, Marc, and Gentry, James W., "An Exploratory Study of Lottery Playing, Gambling addiction, and Links to Compulsive Consumption," in Advances in Consumer Research, Vol. XVII. Jerry C. Olson (Ed.), Ann Arbor, MI: Association for Consumer Research, pp. 298-305, 1990.

3. Csikszentmihalyi, Mihaly, Beyond Boredom and Anxiety, Jossey-Bass, San Francisco, 1975.

4. Deci, Edward L., Intrinsic Motivation, Plenum, New York, 1975.

5. Edmondson, Brad, "Demographics of Gambling," American Demographics, Vol. 39, pp. 40-41, 50-53, 1986.

6. Enscoe, David, "Sweepstakes Are Addictive," Target Marketing, Vol. 13(3), pp. 14-17, 1990.

7. Faber, Ronald J., O'Guinn, Thomas C. and Krych, Raymond, "Compulsive Consumption," in Advances in Consumer Research, Vol. XIV. Melanie Walendorf and Paul Anderson (Eds.), Association for Consumer Research, Ann Arbor, MI., pp. 132-135, 1987.

8. Faison, Edmund W. J., "The Neglected Variety Drive: A Useful Concept for Consumer Behavior," The Journal of Consumer Research, Vol. 4, pp. 172175, 1977.

9. Flanagan, Joseph P., "Sales Promotion: The Emerging Alternative to Brand Building Advertising," The Journal of Consumer Marketing, Vol. 5, pp. 4548, 1988.

10. Gould, James S., "What Do Consumers Really Think About Sweepstakes?" Sales and Marketing Management in Canada, Vol. 29, pp. 28-29, 35, May 1988.

11. Hartley, Steven W. and Cross, James, "How Sales Promotion Can Work For and Against You," Journal of Consumer Marketing, Vol. 5, pp. 35-42,
1988.

12. Hirschman, Elizabeth C., "Experience Seeking: A Subjectivist Perspective of Consumption," Journal of Business Research, Vol. 12, pp. 115-136, 1984.

13. Holbrook, Morris M. and Hirschman, Elizabeth C., "The Experiential Aspects of Consumption: Consumer Fantasies, Feelings, and Fun," Journal of Consumer Research, Vol. 9, pp. 132-140, 1982.

14. Howard, Daniel J., and Barry, Thomas E., "The Evaluative Consequences of Experiencing Unexpected Favorable Events," Journal of Marketing Research, Vol. 27, pp. 51-60, 1990.

15. Incentive, "Facts Survey: Consumer Incentives," Incentive, Vol. 163, No. 5, pp. 42-47, 1990.

16. Jagoda, Don and Daykin, Len, "Sweepstakes and Contests: The Bottom Line Is Promotional Excitement," In Ulanoff, Stanley M. (Ed.), Handbook of Sales Promotion, New York: McGraw Hill, pp. 105127, 1985.

17. Kallick-Kaufmann, Maureen, "The Micro and Macro Dimensions of Gambling in the United States," The Journal of Social Issues, Vol. 35, pp. 7-27, 1979.

18. Klecka, William R., Discriminant Analysis, Sage, Beverly Hills, California, 1980.

19. McConkey, William C. and Warren, William E., "Psychographic and Demographic Profiles of State Lottery Ticket Purchasers," Journal of Consumer Affairs, Vol. 21, pp. 314-327, 1987.

20. Narayana, Chem L. and Raju, P.S., "Gifts Versus Sweepstakes: Consumer Choices and Profiles," Journal of Advertising, Vol. 14, pp. 50-53, 1985.

21. Raju, P. S., "Optimal Stimulation Level: Its Relationship to Personality, Demographics, and Exploratory Behavior," Journal of Consumer Research, Vol. 7, pp. 272-282, 1980.

22. Raju, P. S. and Venkatesen, M., "Exploratory Behavior in the Consumer Context: A State of the Art Review," in Advances in Consumer Research, Vol. VII. Jerry C. Olson (Ed.), Association for Consumer Research, Ann Arbor, Michigan, pp. 258263, 1980.

23. Schultz, Don E. and Robinson, William G., Sales Promotion Management, Crain Books, Chicago, Illinois, 1982.

24. Sheth, Jagdesh N., The Surpluses and Shortages in Consumer Behavior Theory and Research. Journal of the Academy of Marketing Science, Vol. 7, pp. 414427, 1979.

25. Stang, Roger A., "Sales Promotion-Fast Growth, Faulty Management," Harvard Business Review, Vol. 54, pp. 115-124, 1976.

26. Stern, Amiee, "The Promo Wars, "Business Month, July, 1987, pp. 44-46.

27. Ward, James C., and Hill, Ronald Paul, "Designing Effective Promotional Games: Opportunities and Problems," Journal of Advertising, Vol. 20, pp. 69-81, 1991.

28. Wells, Chris, "America's Gambling Fever," Business Week, April 24, 1989, pp. 112-120.

29. Zuckerman, Marvin, Sensation Seeking: Beyond the Optimal Level of Arousal, Lawrence Erlbaum, Hillsdale, N. J., 1979. 